\title{
Article \\ Genetic Engineering of Streptomyces ghanaensis ATCC14672 for Improved Production of Moenomycins
}

\author{
Roman Makitrynskyy *, Olga Tsypik and Andreas Bechthold *D \\ Department of Pharmaceutical Biology and Biotechnology, Institute of Pharmaceutical Sciences, \\ Albert-Ludwigs University, 79104 Freiburg, Germany; olga.tsypik@pharmazie.uni-freiburg.de \\ * Correspondence: roman.makitrynskyy@pharmazie.uni-freiburg.de (R.M.); \\ andreas.bechthold@pharmazie.uni-freiburg.de (A.B.)
}

Citation: Makitrynskyy, R.; Tsypik, O.; Bechthold, A. Genetic Engineering of Streptomyces ghanaensis ATCC14672 for Improved Production of Moenomycins. Microorganisms 2022, 10, 30. https://doi.org/10.3390/ microorganisms10010030 Academic Editor: J.H. de Winde Received: 19 November 2021 Accepted: 20 December 2021 Published: 24 December 2021

Publisher's Note: MDPI stays neutral with regard to jurisdictional claims in published maps and institutional affiliations.

Copyright: (C) 2021 by the authors. Licensee MDPI, Basel, Switzerland. This article is an open access article distributed under the terms and conditions of the Creative Commons Attribution (CC BY) license (https:// creativecommons.org/licenses/by/ $4.0 /)$.
Abstract: Streptomycetes are soil-dwelling multicellular microorganisms famous for their unprecedented ability to synthesize numerous bioactive natural products (NPs). In addition to their rich arsenal of secondary metabolites, Streptomyces are characterized by complex morphological differentiation. Mostly, industrial production of NPs is done by submerged fermentation, where streptomycetes grow as a vegetative mycelium forming pellets. Often, suboptimal growth peculiarities are the major bottleneck for industrial exploitation. In this work, we employed genetic engineering approaches to improve the production of moenomycins $(\mathrm{Mm})$ in Streptomyces ghanaensis, the only known natural direct inhibitors of bacterial peptidoglycan glycosyltransferses. We showed that in vivo elimination of binding sites for the pleiotropic regulator AdpA in the oriC region strongly influences growth and positively correlates with Mm accumulation. Additionally, a marker- and "scar"-less deletion of moeH5, encoding an amidotransferase from the Mm gene cluster, significantly narrows down the Mm production spectrum. Strikingly, antibiotic titers were strongly enhanced by the elimination of the pleiotropic regulatory gene $w b l A$, involved in the late steps of morphogenesis. Altogether, we generated Mm overproducers with optimized growth parameters, which are useful for further genome engineering and chemoenzymatic generation of novel Mm derivatives. Analogously, such a scheme can be applied to other Streptomyces spp.

Keywords: Streptomyces; moenomycin; natural products; AdpA; oriC; WblA; antibiotic; morphology; regulation

\section{Introduction}

The members of the genus Streptomyces are well known as one of the richest sources of biologically active secondary metabolites of microbial origin [1]. Because of their saprophytic lifestyle, streptomycetes are also able to decompose plenty of naturally occurring polymers by producing and exporting various hydrolytic enzymes outside the cells. Some of those enzymes are of high industrial interest, such as cellulases, proteases and amylases [2]. These unique attributes explain the intensive research and strong industrial interest in Streptomyces biology.

In contrast to most bacteria, streptomycetes are multicellular microorganisms, which are also notable for their complex morphological differentiation [3]. Normally, their life cycle begins from a spore, which germinates in the germ tubes, encountering favorable conditions and nutrients. These germ tubes grow by tip extension, forming thread-like structures named hyphae. New hyphae develop via subapical branching, leading to the formation of a dense complex of interconnected hyphae called a vegetative mycelium. In response to certain signals, such as nutrient depletion, morphological differentiation is initiated in a form of long non-fragmented aerial hyphae, which rise from the vegetative mycelium. The entire life cycle culminates with a regular septation of aerial hyphae in separate compartments, which ultimately develop into long chains of mature spores [4]. 
In a submerged environment streptomycetes typically grow in a form of vegetative mycelium, predominantly forming dense particles or clumps [5]. In contrast to unicellular bacteria such as Escherichia coli and Bacillus spp., the Streptomyces growth type is less attractive from a biotechnological point of view, for several reasons. Particularly, such growth results in mass- and heat-transfer problems, and in oxidative stress [6,7]. These consequentially lead to slow growth rates, highly viscous cultures and high culture heterogeneity [8]. Large mycelial clumps are mainly physiologically active around the edge of the pellet, with a significant restriction of the effective transfer of nutritionals and gases to its center [9]. Formation of pellets is a complex process, which includes two major factors-aggregation of germinating spores and pellet fragmentation-influencing the final pellet size heterogeneity. Aggregation is driven by glycans associated with cellular surface, encoded by the $c s l A / g l x A$ operon and the mat cluster [10-12], whereas pellet fragmentation consists of the detachment of mycelial portions from pre-existing particles [13].

Streptomyces ghanaensis ATCC14672 is famous for the production of Mm, a mixture of similar phosphoglycolipid antibiotics with a unique mechanism of action. Acting as the only known direct inhibitors of bacterial peptidoglycan glycosyltransferases-the enzymes involved in the penultimate step of cell wall biosynthesis-Mm have been considered to serve as the blueprint for the development of a novel class of antibacterials [14,15]. In addition to the very low amounts of Mm normally produced by S. ghanaensis, the strain also forms large mycelial particles growing in submerged cultures [15]. This forces the studies aimed to construct strains with higher Mm production titers and better growth characteristics. To achieve this, several heterologous hosts were successfully utilized to express the Mm biosynthetic gene cluster (moe cluster); however, the level of $\mathrm{Mm}$ biosynthesis was still lower than in the wild type [16,17]. Several studies have been undertaken to explore the regulation of Mm biosynthesis. Interestingly, regulatory genes are not present in the moe cluster and numerous global regulators were shown to influence $\mathrm{Mm}$ production [16-26]. A central role in the regulation of Mm biosynthesis belongs to the pleiotropic regulator $\mathrm{Adp}_{\mathrm{gh}}$, which was shown to directly activate the transcription of moe genes [19]. Orthologs of AdpA are omnipresent and highly conserved in Streptomyces and control the expression of numerous genes involved in morphogenesis and both primary and secondary metabolism [27,28]. Interestingly, a study in Streptomyces coelicolor also demonstrated a capacity of AdpA to inhibit the chromosome replication at the initial stage by binding to the replication origin (oriC), thus decreasing the access of the initiator protein (DnaA) [29]. Furthermore, deletion of $w b l A$, a gene encoding a small Fe-S-containing cluster regulatory protein, drastically affects the antibiotic biosynthesis in many streptomycetes, including Mm production [18,24,30-34].

In this work, we applied genetic engineering approaches to construct a series of S. ghanaensis strains where the beneficial changes were sequentially combined, enabling the generation of a triple mutant strain with significantly improved growth particularities and $\mathrm{Mm}$ production titers. We showed that $\mathrm{AdpA}_{\mathrm{gh}}$ plays an important role in the regulation of chromosome replication, thus crucially influencing the growth type of $S$. ghanaensis. Based on this observation, we created a mutant strain with deletion of amidotransferase moeH5, leading to accumulation of a significantly narrowed spectrum of Mm. Finally, we eliminated the negative regulator of $\mathrm{Mm}$ biosynthesis $w b l \mathrm{~A}$ to increasing antibiotic production levels. Overall, our findings set up a putative strategy for optimizing the natural products biosynthesis in other strains.

\section{Materials and Methods}

\subsection{Bacterial Strains, Plasmids and Growth Conditions}

Table S1 contains a list of bacterial strains and DNA constructs used in this work. Escherichia coli strains were grown in Luria-Bertani (LB) medium at $37^{\circ} \mathrm{C}$. Soya mannitol agar (SFM), oatmeal agar (OAT) and tryptic soy broth (TSB) liquid or agar (TSA) media were used to grow S. ghanaensis. Where necessary, the media were supplemented with appropriate antibiotics. 


\subsection{DNA Manipulation}

Routine cloning manipulations were made in E. coli XL1-Blue according to standard procedures [35]. Polymerase chain reactions (PCR) were done using Phusion polymerase (ThermoFisher, Waltham, MA, USA) according to the manufacturer's recommendations, with the set of primers listed in Table S2. Isolation of plasmid/chromosomal DNA was carried out following standard procedures [35]. Verification of DNA constructs was performed using DNA mapping with endonucleases of restriction, PCR and sequencing.

\subsection{Intergeneric Conjugation with E. coli}

E. coli ET12567 (pUZ8002) was used as a donor for conjugal transfer of plasmids into $S$. ghanaensis strains. Fresh recipient spore suspension was harvested from 7-day-old S. ghanaensis strains grown on OAT at $37^{\circ} \mathrm{C}$. After a 10 min heat shock at $50{ }^{\circ} \mathrm{C}$, spores $\left(4 \times 10^{7} \mathrm{cfu}\right)$ were mixed with $E$. coli cells $\left(1 \times 10^{8} \mathrm{cfu}\right)$ carrying the different vectors and then plated on SFM supplemented with $60 \mathrm{mM} \mathrm{CaCl}_{2}$. Next, after $15 \mathrm{~h}$ of incubation at 28 or $37^{\circ} \mathrm{C}$ (depending on a vector), plates were overlaid with $1 \mathrm{~mL}$ of water containing $1.6 \mathrm{mg}$ of apramycin and $5 \mathrm{mg}$ of phosphomycin. Usually, exconjugants appeared after 3 to 5 days of incubation. Nonsporulating mutant strains were first pre-grown in TSB for $24 \mathrm{~h}$ and then $1 \mathrm{~mL}$ of the resulting culture $\left(\sim 3 \times 10^{7} \mathrm{cfu}\right)$ was directly mixed with donor cells using the aforementioned procedure.

\subsection{Microscopy}

The mycelial morphology of $S$. ghanaensis in liquid-grown cultures was monitored using a Carl Zeiss Axiolab 1 microscope. For scanning electron microscopy (SEM), slices of S. ghanaensis lawns were cut off SFM agar plates and directly analyzed on a Quanta 250 environmental scanning electron microscope (ThermoFisher).

\subsection{Generation of Mutant Strains}

\subsubsection{Construction of $S$. ghanaensis $\mathrm{O} 1$}

To construct a mutant strain, where $\mathrm{AdpA}_{\mathrm{gh}}$ bs in the oriC region of the $S$. ghanaensis chromosome were substituted to a nonsense sequence, the following scheme was used. Firstly, a 3-kb-long DNA fragment, consisting of Adp $\mathrm{A}_{\mathrm{gh}}$ bs plus two 1.5-kb-long regions of homology, was amplified from the $S$. ghanaensis chromosomal DNA by PCR using primers oriC_for/oriC_rev. The obtained amplicon was digested with XbaI and EcoRV and cloned into XbaI-EcoRV-cleaved pBluescriptKS+ to give pBloriC. In order to mutate $\mathrm{AdpA}_{\mathrm{gh}} \mathrm{bs}$, PCR mutagenesis was applied to amplify a $6 \mathrm{~kb}$ DNA fragment from pBloriC with primers oriC_mut_for/oriC_mut_rev. The obtained PCR fragment was first treated with T4 polynucleotide kinase and then self-ligated giving pBloriC-mut. Next, pBloriC-mut was cut with $\mathrm{XbaI}$ and EcoRV, and the resulting $3 \mathrm{~kb}$ DNA fragment was ligated into the respective sites of pKG1139, a vector based on a thermosensitive $p S G 5$ replicon carrying a reporter gusA gene [36]. The final plasmid pKGoriC-mut was conjugally transferred into $S$. ghanaensis. To promote an integration of pKGoriC-mut into the S. ghanaensis chromosome via homologous recombination, one exconjugant was inoculated in $15 \mathrm{~mL}$ of TSB containing apramycin. Five passages were conducted, where after each $24 \mathrm{~h}$ of growth at $40^{\circ} \mathrm{C}$ (nonpermissive temperature for the $p S G 5$ replication), $10 \mu \mathrm{L}$ of the culture was inoculated into a fresh medium with apramycin. Next, $1 \mathrm{~mL}$ of the resulting culture was plated on oatmeal agar. After seven days of incubation at $37^{\circ} \mathrm{C}$, serial dilutions of spore suspension were plated on SFM supplemented with 5-bromo-4-chloro-3-indolyl-D-glucuronide (X-Gluc) solution $\left(50 \mu \mathrm{g} \mathrm{mL}{ }^{-1}\right)$. White colonies (indication of vector lost) were checked for the sensitivity to apramycin and then subjected to the PCR analysis. Substitution of $\mathrm{AdpA}_{\mathrm{gh}}$ bs was confirmed by sequencing, leading to the creation of $S$. ghanaensis $\mathrm{O} 1$. 


\subsubsection{Construction of $S$. ghanaensis $\mathrm{O} 1 \Delta \mathrm{H} 5$}

To delete moeH5 from the $S$. ghanaensis $\mathrm{O} 1$ chromosome, a $6.4 \mathrm{~kb}$ DNA fragment comprising moeH5 with two 2.4-kb-long regions of homology was PCR synthesized from the chromosome using primers moeH5_for/moeH5_rev. The resulting amplicon was ligated into pBluescriptKS+ cleaved with EcoRV to give pBlmoeH5. Next, PCR mutagenesis was used to remove the moeH5 coding sequence. To do this, a pair of primers, moeH5_mut_f/moeH5_mut_r, was used to amplify a $7.8 \mathrm{~kb}$ DNA fragment comprising no moeH5 gene from $\mathrm{pBlmoeH} 5$. Next, the PCR product was treated with $\mathrm{T} 4$ polynucleotide kinase and self-ligated, yielding pBl $\Delta$ moeH5. A $4.8 \mathrm{~kb}$ DNA fragment was cut out of $\mathrm{pBl} \Delta \mathrm{moeH} 5$ using XbaI-EcoRV and ligated into the respective sites of pKG1139, creating pKG $\Delta$ moeH5. Then, pKG $\Delta$ moeH5 was transferred to $S$. ghanaensis O1 by intergeneric conjugation with $E$. coli. Screening for double crossover mutants was done as described above, giving a mutant strain $S$. ghanaensis $\mathrm{O} 1 \Delta \mathrm{H} 5$.

\subsubsection{Construction of $S$. ghanaensis $\mathrm{O} 1 \Delta \mathrm{H} 5 \Delta \mathrm{wblA}$}

To generate a triple mutant with a wblA deletion, the analogous scheme was used. First, a $4.3 \mathrm{~kb}$ DNA fragment, consisting of $w b l A$ with two $2 \mathrm{~kb}$ flanking regions of homology, was amplified from the $S$. ghanaensis chromosome by PCR using the primers wblA_for/wblA_rev. The amplicon was ligated into pBluescriptKS+ cut with EcoRV to give pBlwblA. Then, PCR mutagenesis was done to generate a $6.9 \mathrm{~kb}$ fragment (containing no $w b l A$ ) from pBlwblA with the primers wblA_mut_f/wblA_mut_r. It was subsequently treated with $\mathrm{T} 4$ polynucleotide kinase and self-ligated to create $\mathrm{pBl} \Delta$ wblA. A $4 \mathrm{~kb}$ XbaI-EcoRV cut DNA fragment was retrieved from $\mathrm{pBl} \Delta \mathrm{wblA}$ and then cloned into pKG1139 digested with the respective enzymes to give pKG $\Delta \mathrm{wblA}$. The final construct was conjugally transferred to S. ghanaensis $\mathrm{O} 1 \Delta \mathrm{H} 5$ and screening for the mutants was conducted as mentioned above. This resulted in construction of S. ghanaensis $\mathrm{O} 1 \Delta \mathrm{H} 5 \Delta$ wblA.

\subsection{Analysis of Mm Production}

Cultivation of S. ghanaensis strains, Mm extraction and analysis of Mm production were performed according to the previously established protocols [17]. Routine quantification of Mm production levels was done on a UHPLC Thermo Fisher Scientific Ultimate 3000 SD system equipped with an automated liquid sampler, a diode array detector, and a TSQ Quantum Access MAX ESI mass spectrometer with a reversed-phase Nucleodur 100-5 C18ec column (Macherey-Nagel, $5 \mu \mathrm{m}, 150 \times 2 \mathrm{~mm}$ ), as described before [24]. Four major compounds were monitored via LC-MS in S. ghanaensis WT extracts: $\mathrm{MmA}\left(\mathrm{MmA} ; m / z=789.8[\mathrm{M}-2 \mathrm{H}]^{2-}\right)$, nosokomycin B (NoB; $\left.m / z=741.8[\mathrm{M}-2 \mathrm{H}]^{2-}\right)$, moenomycin $\mathrm{G}\left(\mathrm{MmG} ; m / z=770.8[\mathrm{M}-2 \mathrm{H}]^{2-}\right)$ and desmethylated $\mathrm{NoB}\left(\mathrm{dNoB} ; m / z=734.8[\mathrm{M}-2 \mathrm{H}]^{2-}\right)$, whereas nosokomycin A (NoA; $\left.m / z=742.3[\mathrm{M}-2 \mathrm{H}]^{2-}\right)$ and desmethylated NoA $\left(\mathrm{dNoA} ; m / z=735.3[\mathrm{M}-2 \mathrm{H}]^{2-}\right)$ were monitored in the strains carrying moeH5 deletion.

For qualitative analysis of extracts from S. ghanaensis, a reversed-phased InfinityLab Poroshell 120 EC-C18 column (Agilent, $2.7 \mu \mathrm{m}, 3.0 \times 150 \mathrm{~mm}$ ) was employed with the following mobile system: phase $\mathrm{A}$-water and mobile phase $\mathrm{B}-\mathrm{MeCN}$, both with $0.5 \%$ acetic acid (vol/vol) as a solvent modifier. The solvents were delivered at $0.5 \mathrm{~mL} / \mathrm{min}$ under a gradient elution program: 0 min 95\% A, $0.5 \mathrm{~min} 95 \%$ A, $23 \mathrm{~min} 5 \%$ A, $26.5 \mathrm{~min}$ $5 \% \mathrm{~A}, 27 \mathrm{~min} 95 \% \mathrm{~A}$, and $30 \mathrm{~min} 95 \% \mathrm{~A}$. The mass spectrometer was operated in negative ESI mode using the parameters described earlier [24].

\section{Results}

3.1. Substitution of $A d p A_{g h}$ bs in oriC In Vivo Drastically Influences the Growth Particularities and $\mathrm{Mm}$ Production in S. ghanaensis

In S. ghanaensis biosynthesis of $\mathrm{Mm}$ is strictly depended on the $\mathrm{AdpA}_{\mathrm{gh}}$ activity, where it directly activates the transcription of key moe genes [19]. Moreover, in S. coelicolor 
AdpA binds to the oriC region, thus inhibiting chromosome replication [29]. Therefore, we aimed to evaluate whether substitution of $\mathrm{AdpA}_{\mathrm{gh}} \mathrm{bs}$ in oriC influences growth and $\mathrm{Mm}$ production in $S$. ghanaensis. For this purpose, we first compared the oriC regions between S. ghanaensis and S. coelicolor for the presence of AdpAbs. As depicted in Figure 1, the nucleotide sequence of the $S$. ghanaensis DNA region, responsible for AdpA and DnaA binding, shares a high degree of similarity to that of S. coelicolor [29]. Particularly, there are two divergently oriented and partially overlapped putative $\mathrm{AdpA}_{\mathrm{gh}} \mathrm{bs}$ (Figure 1). Analogous to S. coelicolor, they are located in the proximate vicinity of the DnaA binding sites (DnaAbs), indicating their involvement in the regulation of chromosome replication. It was shown that AdpA binding led to the extended protection of the DNA region and thus reduce accessibility of DnaAbs to the DnaA initiator protein [29]. Previous work on the Streptomyces lividans 66 oriC region suggested that replication of its chromosome depends on all DnaAbs, including those that surround AdpAbs [37] (Figure 1).

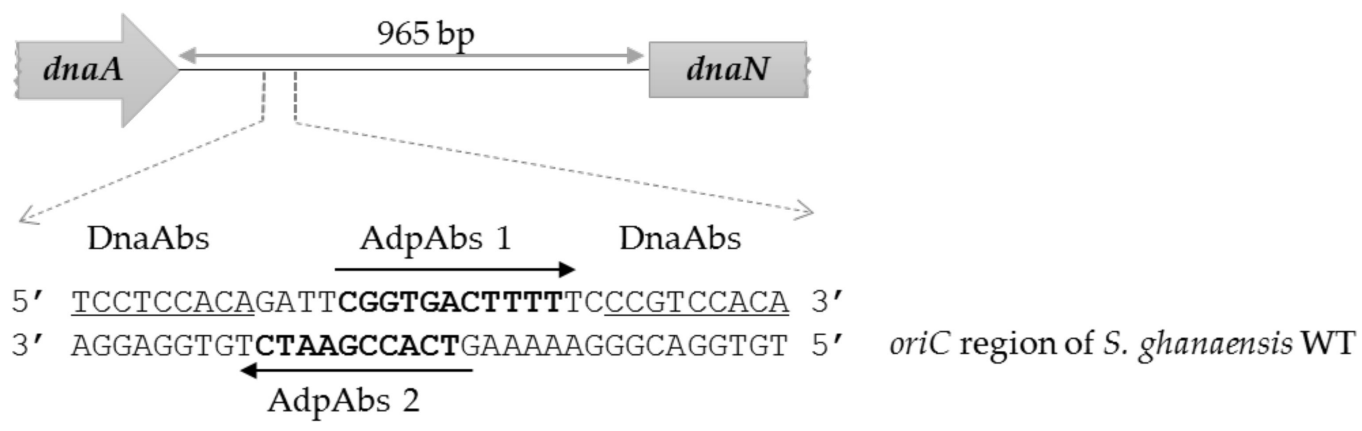

DnaAbs

DnaAbs

5' TCCTCCACACCCATATGACCTTTTTCCCGTCCACA 3'

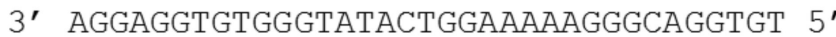

oriC region of $\mathrm{S}$. ghanaensis $\mathrm{O} 1$

Figure 1. Schematic representation of the $S$. ghanaensis oriC region. Putative DnaA binding sites are underlined, whereas AdpAbs are in bold. The distance between the start and stop codons is shown.

Therefore, to test the role of $\mathrm{AdpA}_{\mathrm{gh}} \mathrm{bs}$ in the $\mathrm{Mm}$ production and growth of S. ghanaensis, we employed a PCR mutagenesis-based strategy (see Materials and Methods) to eliminate the overlapping $\mathrm{Adp}_{\mathrm{gh}} \mathrm{bs} 1$ and 2 in vivo. We substituted them for a nonsense sequence in a way that the distance between two adjacent DnaAbs remained intact (Figure 1). The resulting $S$. ghanaensis strain carrying a mutation in both $\mathrm{AdpA}_{\mathrm{gh}} \mathrm{bs}$ was named S. ghanaensis $\mathrm{O} 1$.

Next, we assessed changes in both $\mathrm{Mm}$ and biomass accumulation by S. ghanaensis $\mathrm{O} 1$ in comparison to the wild-type strain. Equal amounts of spores $\left(1 \times 10^{7} \mathrm{cfu}\right)$ were used to initiate the fermentation and then the strains were cultivated in parallel in TSB for four days. Aliquots were collected from the growing cultures at certain time points and were subjected to further analysis. Biomass accumulation was used to monitor the growth dynamic. As shown in Figure 2A, on average, $S$. ghanaensis O1 accumulated two-fold more biomass during the first $20 \mathrm{~h}$ of growth compared to the wild type. Moreover, the mutant strain entered the stationary phase already after $14 \mathrm{~h}$ of growth, whereas it took $22-24 \mathrm{~h}$ to reach it for the wild type. After $30 \mathrm{~h}$ of cultivation, both strains displayed a similar growth pattern, indicating that mutation of $\mathrm{AdpA}_{\mathrm{gh}}$ bs strongly affects the type of growth, especially at early stages.

Following the growth dynamic, we evaluated the Mm production by S. ghanaensis strains. As depicted in Figure 2B, both analyzed strains accumulated relatively equal amounts of Mm after $96 \mathrm{~h}$ of cultivation, an established standard time period for $\mathrm{Mm}$ extraction in S. ghanaensis $[17,19,24,25]$. However, we observed a shift in the dynamic of antibiotic biosynthesis between strains. In comparison to the wild type, S. ghanaensis O1 produced a higher amount of Mm over the first three days of growth and reached its 
maximum after $72 \mathrm{~h}$. After four days of cultivation, a concentration of $\mathrm{Mm}$ in biomass pellet slightly dropped down, most likely due to the cell lysis. In contrast, the control strain gradually accumulated the antibiotic over the entire fermentation time course and gained its highest titer after $96 \mathrm{~h}$ (Figure 2B). The obtained results suggest that binding of $\mathrm{AdpA}_{\mathrm{gh}}$ to oriC strongly influences both growth pattern and time course of Mm biosynthesis in S. ghanaensis.

(A)

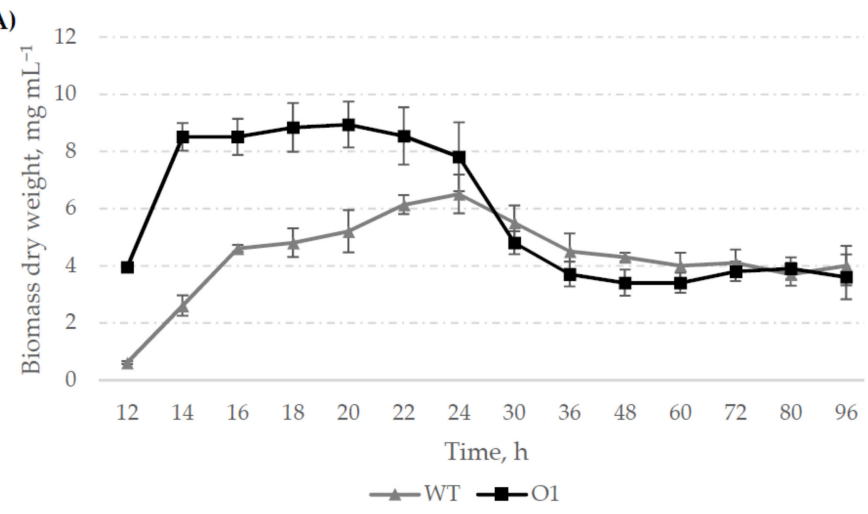

(B)

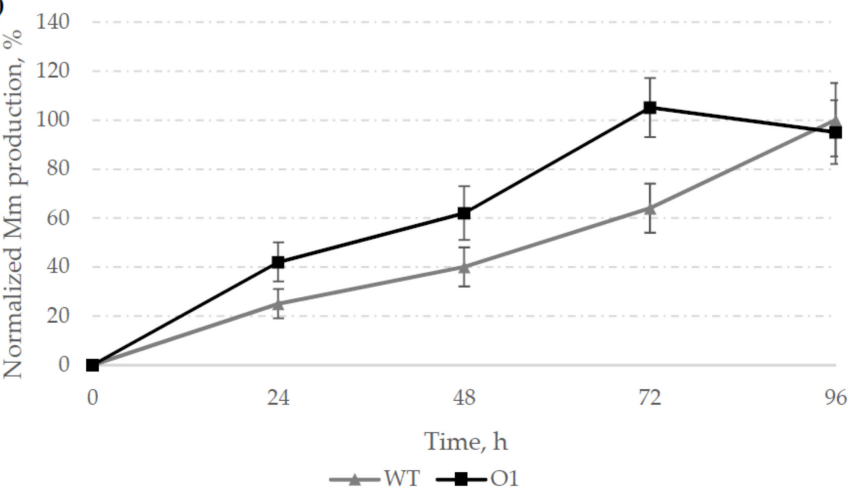

Figure 2. Substitution of $\mathrm{AdpA}_{\mathrm{gh}}$ bs in the oriC region severely affects the growth dynamic and $\mathrm{Mm}$ accumulation in S. ghanaensis. (A) Comparison of the biomass accumulation between the parental S. ghanaensis ATCC14672 (WT) and mutant S. ghanaensis O1 (O1) strains. (B) Dynamic of Mm production in S. ghanaensis ATCC14672 (WT) and S. ghanaensis O1 (O1). Error bars represent standard deviations. Amounts of Mm were normalized to equal amounts of biomass (dry weight) and were the mean values from at least three independent biological replicates. The mean value of the moenomycin mass peak area of the wild type detected after $96 \mathrm{~h}$ of fermentation was taken as $100 \%$.

Following our observations, we decided to check whether mutation of $\mathrm{AdpA}_{\mathrm{gh}}$ bs also affects the morphogenesis. For this purpose, two strains where grown in parallel on a series of media. Interestingly, no pronounced difference, either in growth dynamic or in morphological progression, was observed after four days of cultivation on solid media (Figure 3A). However, after four days of growth, scanning electron microscopy revealed a slightly intensive and denser sporulation in S. ghanaensis O1 (Figure 3B). To investigate this, we calculated a titer of spores formed by the two analyzed strains after four days of incubation on OAT. Indeed, in comparison to the wild type, the mutant strain produced on average $25 \%$ more spores per plate.

Since the most distinct changes in growth particularities were detected during the cultivation of $S$. ghanaensis strains in liquid media, we examined the mycelial morphology of strains grown in TSB. The $S$. ghanaensis wild-type strain typically grows forming large mycelial pellets (Figure S1), which is disadvantage, as such a growth type results in slow nutrient utilization and hampers routine laboratory manipulations. To compare differences in growth dynamic, an equal amount of seeding material (spores, $1 \times 10^{7} \mathrm{cfu}$ ) was inoculated into TSB. Sample aliquots were collected from growing cultures and then mycelial morphology was directly analyzed. The beginning of aggregation of the germinated spores was already noticeable after $2 \mathrm{~h}$ of growth in the wild type, whereas there was a $2 \mathrm{~h}$ delay in S. ghanaensis O1 (data not shown). After $6 \mathrm{~h}$ of growth both strains formed mycelial structures; however, they were bigger and denser in the parental strain (Figure 4). The difference in type of growth became more profound over the time of cultivation. Thus, after $14 \mathrm{~h}$ since the inoculation, individual pellets produced by the wild type started to aggregate, leading to the formation of large mycelial complexes (Figure 4). This tendency continued for the first two days of growth and then the dynamics of pellet fragmentation started to prevail over aggregation. This led to a more dispersed pellet morphology, especially after $48 \mathrm{~h}$ of growth, whereas the mutant strain formed almost no mycelial pellets over the 
entire time course of cultivation, except upon increasing the biomass density patches of the dispersed mycelia entangled in open pellet-like structures (Figure 4).

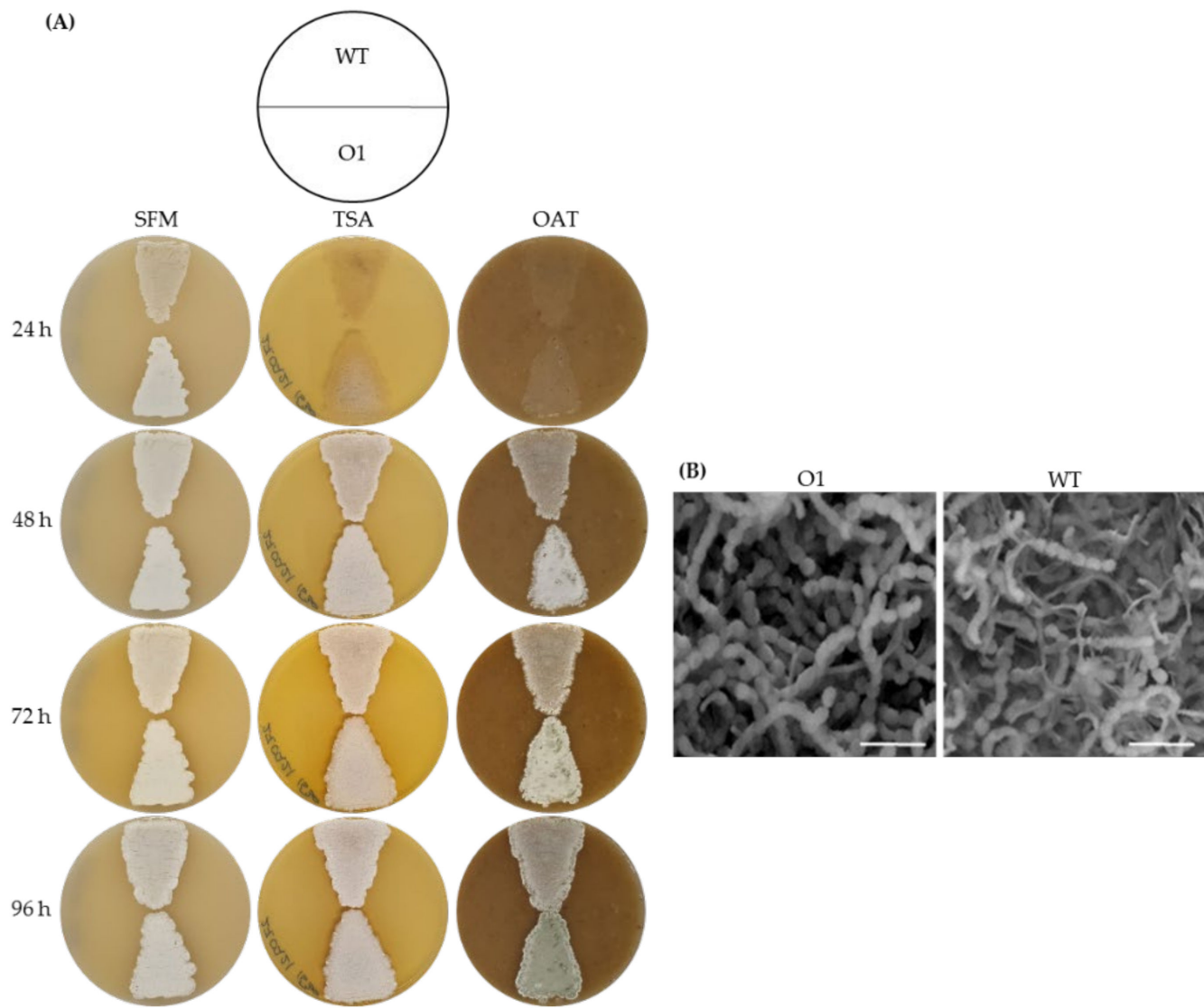

Figure 3. Substitution of $\mathrm{AdpA}_{\mathrm{gh}} \mathrm{bs}$ in the oriC region has a little effect on morphological progression. (A) Phenotypes of S. ghanaensis ATCC14672 (WT) and S. ghanaensis O1 (O1) cultivated on SFM, TSA and OAT solid media at $37^{\circ} \mathrm{C}$. (B) More intensive sporulation observed in S. ghanaensis O1 (O1) in comparison to the wild type (WT) using SEM. Surfaces of the lawns from (A) grown on OAT for $96 \mathrm{~h}$ were used to obtain SEM images. Scale bars correspond to $5 \mu \mathrm{m}$.

The dispersed growth of $S$. ghanaensis O1, an accelerated growth rate, a shorter duration of fermentation along with an increased $\mathrm{Mm}$ accumulation are clearly beneficial over the parental strain. This set up a starting point for further manipulations to improving the Mm production in S. ghanaensis.

3.2. A Marker- and "Scar"-less Deletion of Amidotransferase Gene moeH5 Narrows down the Spectrum of Mm Produced by S. ghanaensis O1 $\Delta H 5$

A complex of Mm produced by S. ghanaensis includes numerous derivatives of MmA, with minor modifications [15]. This not only interferes with the purification of desired compounds but also significantly hinders the quantification of antibiotic production during routine lab manipulations. The structural heterogeneity of $\mathrm{Mm}$ in S. ghanaensis is originated from several variables [15]. The majority of Mm contains different portions at the carboxylic acid group of galactopyranuronic acid unit B (Figure 5A). It can be linked either to a 2-aminocyclopentane-1,3-dione ( $\mathrm{C} 5 \mathrm{~N})$ chromophore unit A, or converted into a carboxamide, or extended with glycine, serine, cysteine or alanine. Recently it was shown that the greatest natural diversity in the Mm family of antibiotics is mediated by the amidotransferase MoeH5, which possesses a broad substrate specificity [38]. To reduce a spectrum of Mm typically produced by the wild-type strain, we decided to eliminate moeH5 from the chromosome of S. ghanaensis O1. To construct a marker- and "scar"-free strain, we 
employed a PCR mutagenesis strategy. A moeH5 knockout plasmid was created in a way that allows a "clear" deletion of the entire ORF. Since an upstream gene moeGT1 overlaps with moeH5, only the start, one following and the stop codons remained in the S. ghanaensis $\mathrm{O} 1 \Delta \mathrm{H} 5$ chromosome to keep in frame the DNA sequence.
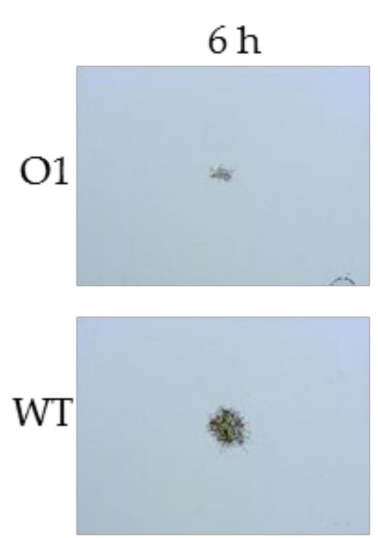

$22 \mathrm{~h}$
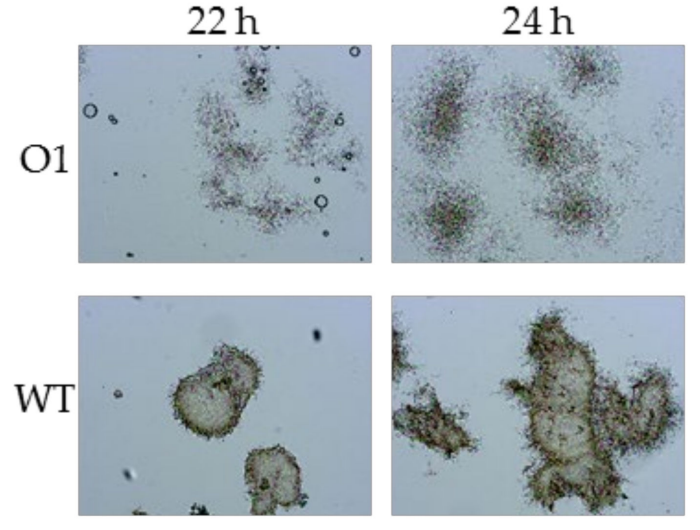

$8 \mathrm{~h}$
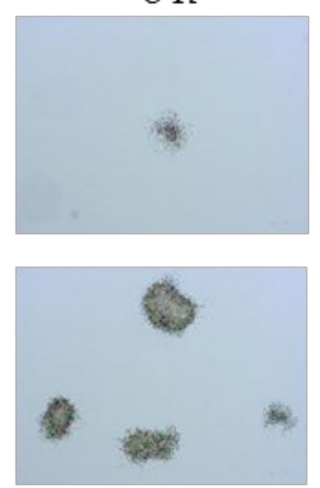

$24 \mathrm{~h}$
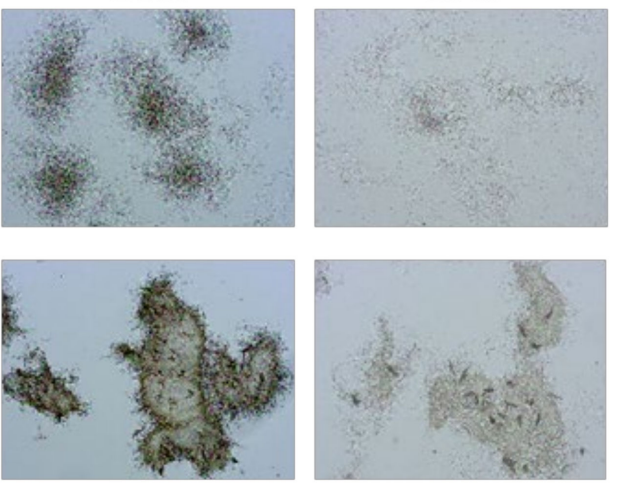
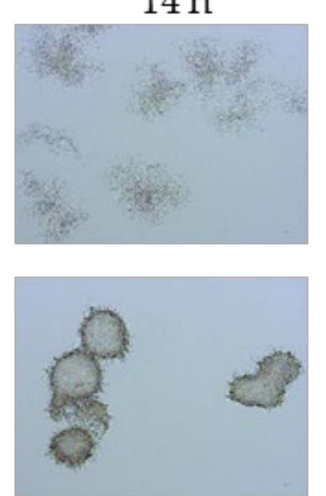

$48 \mathrm{~h}$

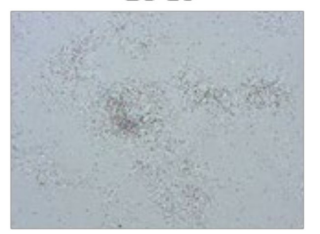

$16 \mathrm{~h}$
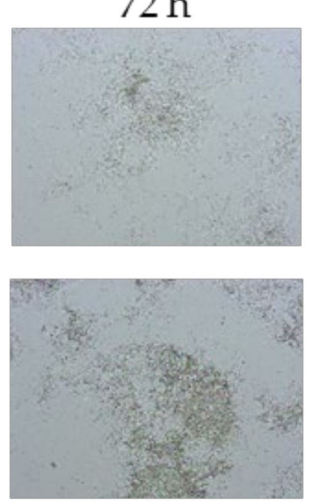

$18 \mathrm{~h}$
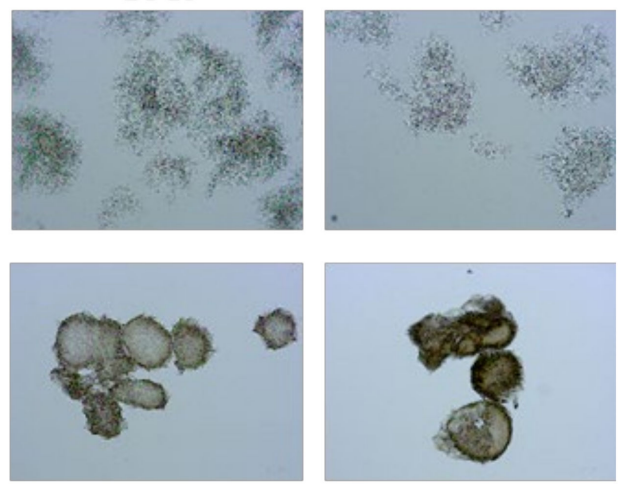

$96 \mathrm{~h}$
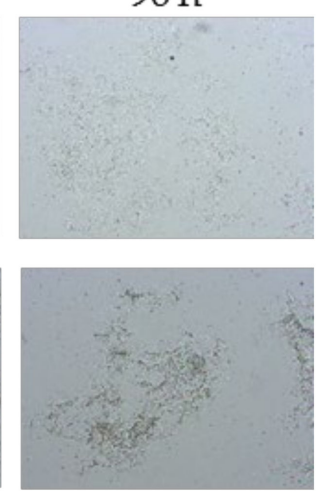

$200 \mu \mathrm{m}$

Figure 4. Liquid-culture morphology of the S. ghanaensis ATCC14672 (WT) and S. ghanaensis O1 (O1) strains grown in TSB for $96 \mathrm{~h}$. The scale bar is $200 \mu \mathrm{m}$.

To compare metabolic profiles of S. ghanaensis $\mathrm{O} 1 \Delta \mathrm{H} 5$ and $\mathrm{O} 1$, both strains were cultivated in TSB for four days. Methanol extracts from the biomass were directly analyzed via UHPLC-MS (Figure 5B). As shown in Figure 5C, in S. ghanaensis O1 the most abundant peaks were negatively double charged ions corresponding to $\mathrm{NoB}(\mathrm{m} / \mathrm{z}=741.8), \mathrm{MmA}$ $(\mathrm{m} / \mathrm{z}=789.8), \mathrm{dNoB}(\mathrm{m} / \mathrm{z}=734.8)$ and $\mathrm{MmG}(\mathrm{m} / \mathrm{z}=770.8)$. A contribution of other $\mathrm{Mm}$ to the total antibiotic production in S. ghanaensis $\mathrm{O} 1$ was relatively low. In contrast to the parental strain, deletion of moeH5 greatly narrowed down Mm spectrum in S. ghanaensis $\mathrm{O} 1 \Delta \mathrm{H} 5$ (Figure 5D). The mutant almost exclusively accumulated NoA $(\mathrm{m} / \mathrm{z}=742.3)$, with a minor fraction of $\mathrm{dNoA}(\mathrm{m} / \mathrm{z}=735.3)$. It is worth noting that there were no obvious changes, either in the growth dynamic or in the timing of morphogenesis between the analyzed strains.

In summary, we constructed the mutant S. ghanaensis $\mathrm{O} 1 \Delta \mathrm{H} 5$ that produces a significantly narrowed spectrum of antibiotics. Additionally, deletion of moeH5 did not introduce any extra DNA (e.g., antibiotic resistance markers, recombinase recognition sites, etc.) in the chromosome of the producing strain, making it easily susceptible for the next genetic manipulations. 
(A)
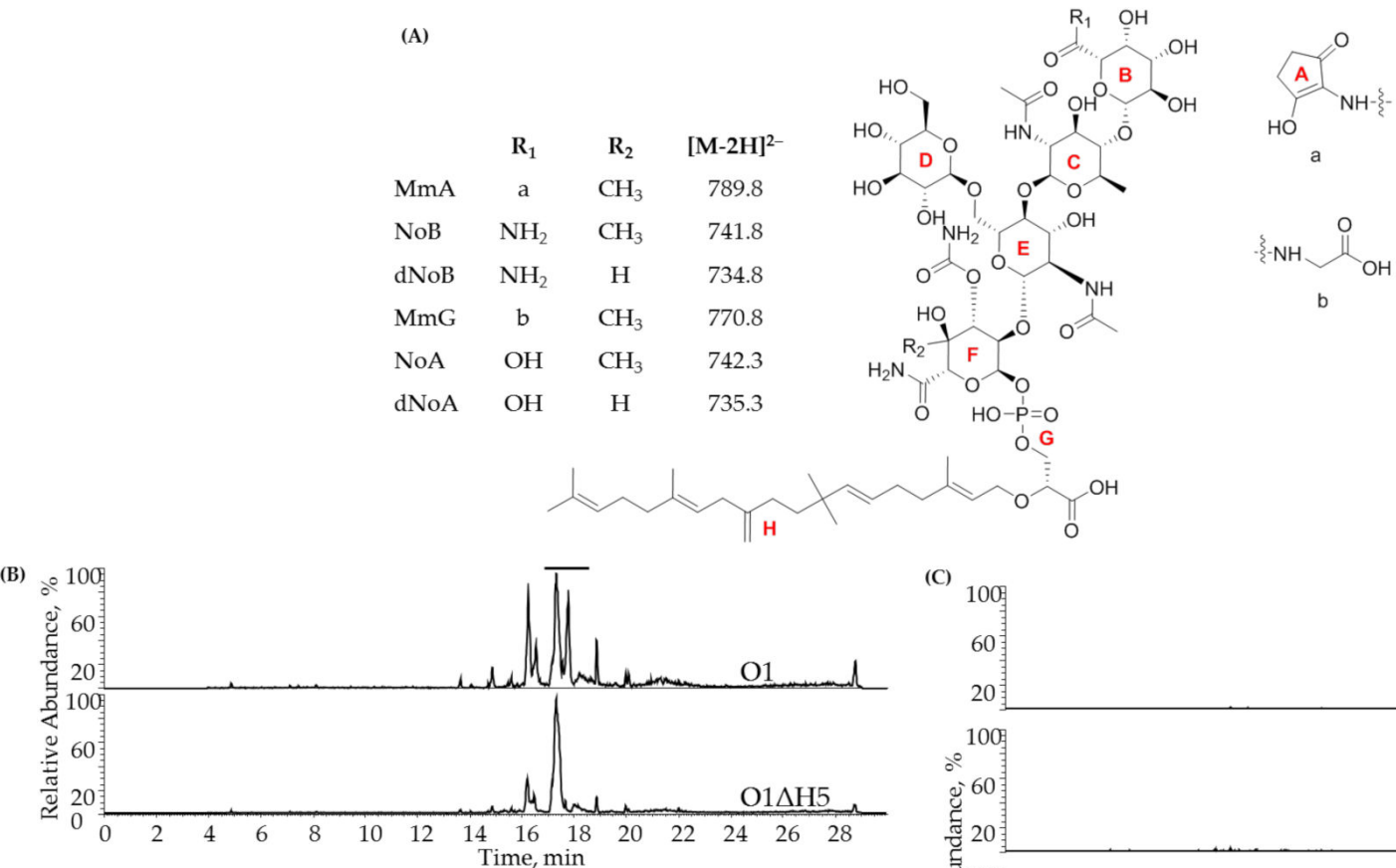

$\begin{array}{lccr} & \mathbf{R}_{1} & \mathbf{R}_{2} & {[\mathbf{M}-2 \mathrm{H}]^{2-}} \\ \text { MmA } & \text { a } & \mathrm{CH}_{3} & 789.8 \\ \text { NoB } & \mathrm{NH}_{2} & \mathrm{CH}_{3} & 741.8 \\ \text { dNoB } & \mathrm{NH}_{2} & \mathrm{H} & 734.8 \\ \text { MmG } & \mathrm{b} & \mathrm{CH}_{3} & 770.8 \\ \text { NoA } & \mathrm{OH} & \mathrm{CH}_{3} & 742.3 \\ \text { dNoA } & \mathrm{OH} & \mathrm{H} & 735.3\end{array}$
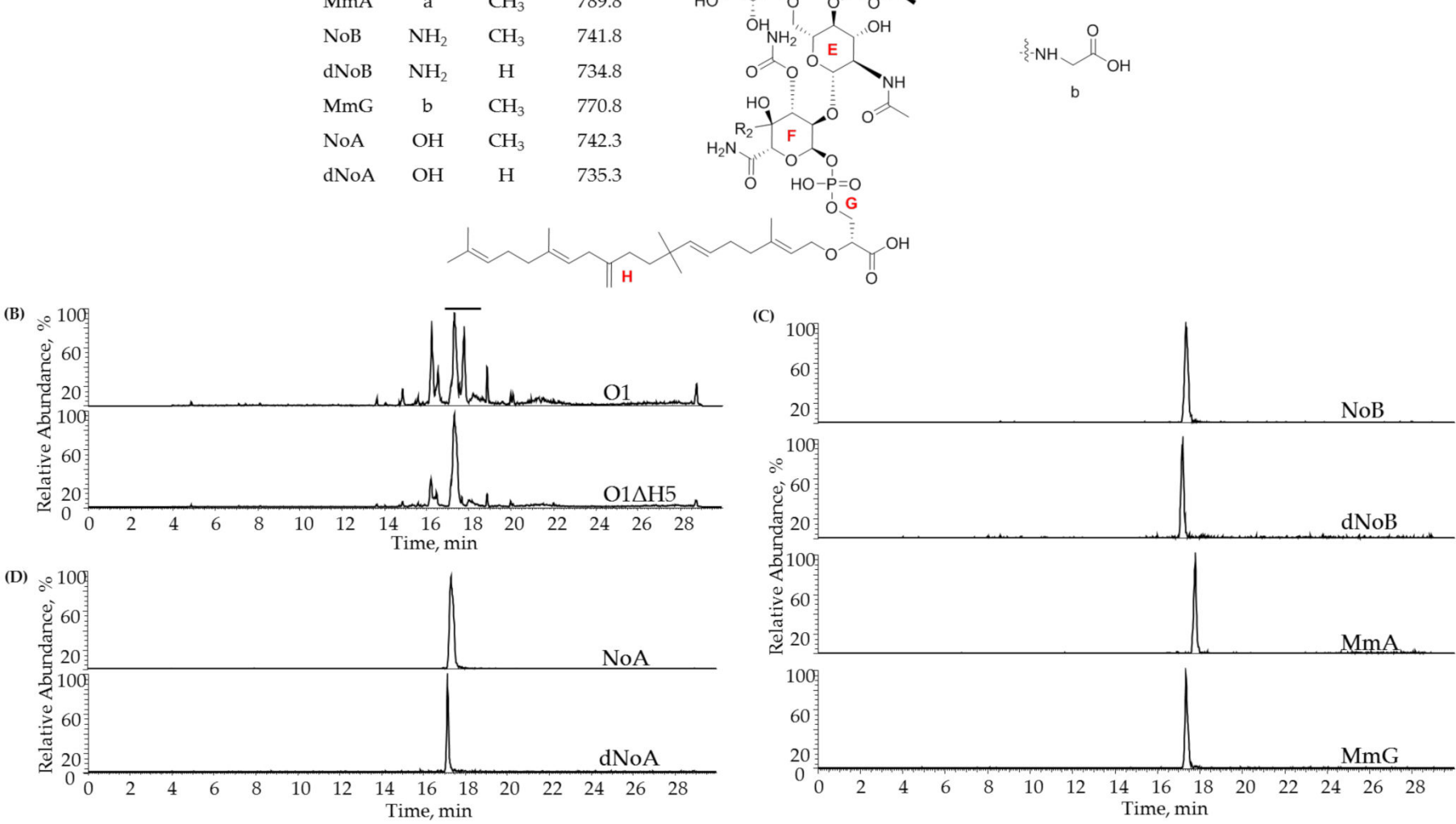

Figure 5. Deletion of the amidotransferase gene moeH5 significantly narrows down the spectrum of Mm produced by S. ghanaensis O1 $\Delta$ H5. (A) Structures of Mm related to this work. (B) LC-MS (TIC) analysis of the methanol extracts from biomass of S. ghanaensis $\mathrm{O} 1(\mathrm{O} 1)$ and S. ghanaensis $\mathrm{O} 1 \Delta \mathrm{H} 5$ $(\mathrm{O} 1 \Delta \mathrm{H} 5)$. Thick blue line corresponds to the Mm retention time. (C) MS extracted ion chromatograms corresponding to main Mm derivatives accumulated in S. ghanaensis O1. (D) The strongly reduced spectrum of Mm produced by S. ghanaensis $\mathrm{O} 1 \Delta \mathrm{H} 5$. Shown are MS extracted ion chromatograms corresponding to NoA and dNoA.

\subsection{Deletion of the Regulatory Gene wbl $A_{g h}$ Strongly Improves NoA Production in S. ghanaensis $01 \Delta H 5 \Delta w b l A$}

Unlike the majority of antibiotic biosynthetic gene clusters, in S. ghanaensis, Mm biosynthesis includes no cluster-situated regulators involved in the regulation of metabolic pathway $[14,17,19]$. This is disadvantageous due to the fact that routine approaches (e.g., overexpression of positive or deletion of negative cluster-situated regulators) are not applicable for improving of $\mathrm{Mm}$ production titers. Many studies have identified numerous global pleiotropic regulators governing $\mathrm{Mm}$ production. One of them-wblA - a gene encoding a Fe-S cluster-containing transcription factor, involved in the late stages of morphological differentiation, was shown to negatively operate Mm synthesis in S. ghanaensis [18,24]. To improve NoA accumulation by $S$. ghanaensis $\mathrm{O} 1 \Delta \mathrm{H} 5$, we created a triple mutant where $w b l A_{g h}$ was deleted from the chromosome via homologous recombination. The gene knockout was performed in the same way as described above, leading to the construction of a marker- and "scar"-less mutant $S$. ghanaensis $\mathrm{O} 1 \Delta \mathrm{H} 5 \Delta \mathrm{wblA}$. 
To compare the production titers of NoA, S. ghanaensis $\mathrm{O} 1 \Delta \mathrm{H} 5 \Delta$ wblA and $\mathrm{O} 1 \Delta \mathrm{H} 5$ were grown in TSB for four days. Extracts from their biomass were subjected to analysis via LC-MS. As depicted in Figure 6A, deletion of $w b l A_{g h}$ significantly improved antibiotic production in $\mathrm{O} 1 \Delta \mathrm{H} 5 \Delta$ wblA compared to the parental strain. On average, the $w b l A_{g h}{ }^{-}$ deficient mutant accumulated 2.6-fold more NoA than the $\mathrm{O} 1 \Delta \mathrm{H} 5$ strain (Figure $6 \mathrm{~B}$ ). In addition, elimination of $w b l A_{g h}$ strongly impaired the morphological progression, as the mutant strain failed to sporulate. In comparison to the control strain, even after prolonged incubation on solid media, the surface of S. ghanaensis $\mathrm{O} 1 \Delta \mathrm{H} 5 \Delta$ wblA remained white, indicating an inability to produce a green spore pigment associated with mature spores (Figure 6C).

(A)

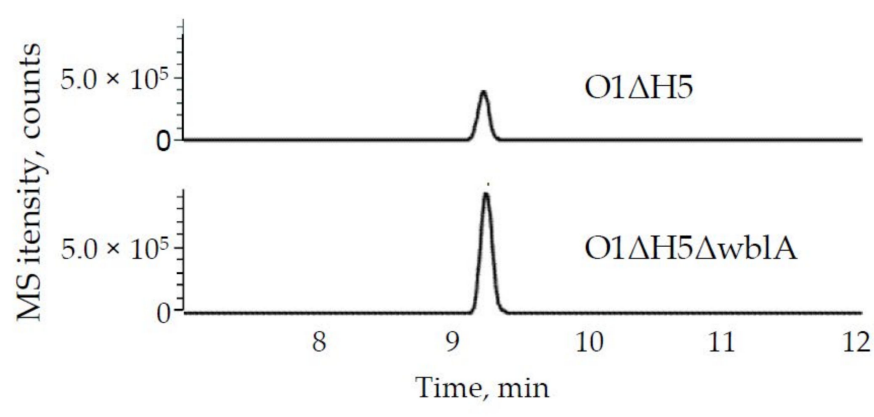

(B)

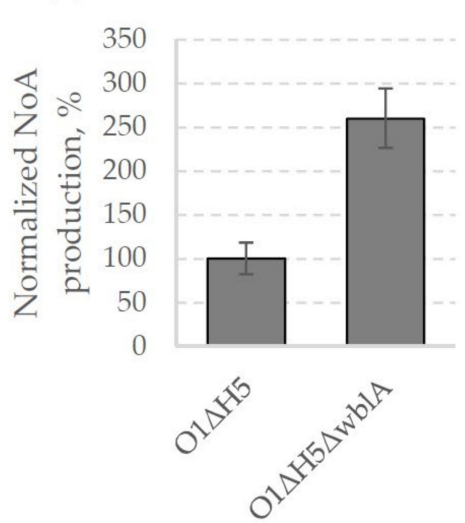

(C)

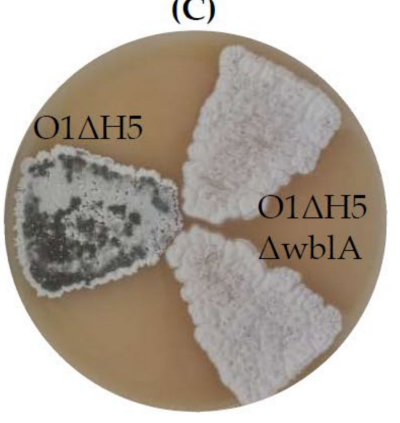

Figure 6. Deletion of $w b l A_{g h}$ drastically affects both NoA accumulation and morphological progression. (A) LC-MS analysis of methanol extracts from biomass of $S$. ghanaensis $\mathrm{O} 1 \Delta \mathrm{H} 5(\mathrm{O} 1 \Delta \mathrm{H} 5)$ and S. ghanaensis $\mathrm{O} 1 \Delta \mathrm{H} 5 \Delta \mathrm{wblA}(\mathrm{O} 1 \Delta \mathrm{H} 5 \Delta \mathrm{wblA})$. Shown are MS extracted ion chromatograms corresponding to NoA $+\mathrm{dNoA}$. (B) NoA $+\mathrm{dNoA}$ production titers by $S$. ghanaensis strain as determined by LC-MS. (C) Inability of $S$. ghanaensis $\mathrm{O} 1 \Delta \mathrm{H} 5 \Delta \mathrm{wblA}$ to produce spores even after prolonged incubation. Strains were grown for 7 days on MS.

\subsection{Comparison of Conjugal Efficacy between E. coli and the Generated Mutant Strains}

Efficiency of DNA introduction into Streptomyces cells is one of the key factors required for the successful genetic manipulations. Among all the available ways of DNA transfer in the genetics of streptomycetes, E. coli-Streptomyces intergeneric conjugation is the most widely used method due to its relative simplicity and high efficiency [39]. Since some of our genetic manipulations drastically changed both the morphology and growth dynamic, we aimed to compare the efficiency of DNA introduction between the generated S. ghanaensis strains. To achieve that, we used two of the most common actinobacterial vectors broadly used in S. ghanaensis [14,24,25]: an integrative $\varphi$ C31-based pSET152 and an oligocopy replicative pKC1139 [39]. It was shown that in S. ghanaensis, pSET152 integrates into attB ${ }^{\varphi C 31}$ only once per genome [40], whereas pKC1139 normally replicates at the temperatures lower than $30^{\circ} \mathrm{C}$ due to the presence of a thermosensitive pSG5 replicon that restricts replication at nonpermissive conditions $\left(\mathrm{t}>36^{\circ} \mathrm{C}\right)$ [41].

The pSET152 ${ }^{+}$and $\mathrm{pKC} 1139^{+}$exconjugants of the $S$. ghanaensis wild type were obtained at a 2.5- and 3-fold lower frequency, respectively, in comparison to S. ghanaensis O1 (Table 1). Next, we tested the exconjugants occurrence using S. ghanaensis $\mathrm{O} 1 \Delta \mathrm{H} 5$ as a recipient. Predictably, there was a little difference in conjugal frequency for both tested vectors with respect to its parental strain S. ghanaensis $\mathrm{O} 1$, since elimination of moeH5 had no influence on the growth characteristics. Lastly, we determined the influence of $w b l A_{g h}$ deletion on the conjugal efficiency. The appearance of exconjugants drastically decreased by 6- and 7-fold for pSET152 and pKC1139, respectively, compared to the parental strain (Table 1). 
Table 1. Frequency of exconjugants occurrence in the S. ghanasensis strains.

\begin{tabular}{ccc}
\hline Strain & pSET152 & pKC1139 \\
\hline S. ghanaensis ATCC14672 & $(4 \pm 0.3) \times 10^{-5}$ & $(5 \pm 0.2) \times 10^{-6}$ \\
S. ghanaensis O1 & $(1 \pm 0.1) \times 10^{-4}$ & $(1.5 \pm 0.2) \times 10^{-5}$ \\
S. ghanaensis O1 $\Delta \mathrm{H} 5$ & $(9 \pm 0.8) \times 10^{-5}$ & $(1.4 \pm 0.3) \times 10^{-5}$ \\
S. ghanaensis O1 $\Delta \mathrm{H} 5 \Delta$ wblA & $(1.6 \pm 0.25) \times 10^{-5}$ & $(2.1 \pm 0.4) \times 10^{-6}$ \\
\hline
\end{tabular}

In summary, elimination of $\mathrm{AdpA}_{\mathrm{gh}} \mathrm{bs}$ in the oriC region strongly improved the efficacy of conjugal transfer using both replicative and integrative vectors. In contrast, deletion of $w b l A_{g h}$, which led to the repression of sporulation in S. ghanaensis, significantly reduced the frequency of exconjugants occurrence.

\section{Discussion}

The worldwide spread of multidrug-resistant pathogens is a rising global problem. Uncontrolled and unreasonable administration of antibacterials over the last several decades have led to the accumulation of superbugs-microorganisms that have developed the ability to resist against commonly prescribed medications. The growing number of superbugs resistant to the cell-wall inhibitor vancomycin is one of the most urgent calls for public health, as this causes a number of deaths around the world annually [42]. Nowadays, novel antibiotics, able to combat multidrug-resistant pathogens, are urgently needed. The introduction of new classes of antibiotics in clinical applications has been limited over the last 40 years because of several reasons [43]. Despite the huge portfolio of biosynthetic gene clusters encoded by actinobacterial genomes, only a small number of NPs are abundantly produced during the laboratory conditions [44]. Many novel techniques have been applied to boost the expression of poorly expressed clusters; however, in most of the cases it tends to rediscovery of known antibiotics [45-49]. This reinforces an interest in promising antibiotics that were discovered many years ago.

Mm belong to a small family of phosphoglycolipid antibiotics that were initially discovered in 1965 [50,51]. Mm inhibits the cell wall biosynthesis in unique way by direct binding to bacterial transglycosylases-the enzymes involved in the last steps of cell wall assembly. In comparison to the clinically used glycopeptide antibiotic vancomycin, $\mathrm{MmA}$ is up to 1000 -fold more potent against various Gram-positive bacteria, including vancomycin-resistant pathogens [52]. Despite their high potency, Mm have never been introduced into clinical practice because of their suboptimal pharmacokinetic properties. It is thought to be mainly due to the presence of the $C_{25}$ carbon chain, leading to their long half-life in the blood stream $[53,54]$. Therefore, several studies have been initiated to construct Mm analogs with improved pharmacokinetics employing both chemoenzymatic and genetic engineering techniques [15]. Numerous derivatives with altered biological activities were created, using the active $\mathrm{Mm}$ pharmacophore as a starting point [55-58]. Taking into account that chemical synthesis of $\mathrm{Mm}$ is challenging [59], the production of novel Mm derivatives through fermentation and/or chemoenzymatic approaches would be highly desirable. Nevertheless, the Mm complex has been widely used as animal growth promoters for cattle, swine and poultry [60]. Strikingly, no profound impact on the $\mathrm{Mm}$ antimicrobial resistance due to an intensive use of $\mathrm{Mm}$ in animal feeding has been observed [54,61].

S. ghanaensis is one of few streptomycetes known for the ability to produce $\mathrm{Mm}$. Many studies have been conducted in order to improve low Mm production levels, including utilization of heterologous hosts for the expression of moe genes $[14,16,17,19,23]$. However, none of the tested hosts were superior over the wild-type strain in terms of Mm productivity. Thus, genetic and metabolic engineering of the native producer would be the logical continuation of the work to construct overproducing strains. However, when grown in submerged cultures, S. ghanaensis typically forms large mycelial pellets. This type of growth is disadvantageous from a biotechnological point of view and it 
complicates routine lab manipulations. In this work, we demonstrate the pivotal role of $\mathrm{AdpA}_{\mathrm{gh}}$ in controlling the $S$. ghanaensis growth type. Substitution of $\mathrm{AdpA}_{\mathrm{gh}}$ bs to a nonsense sequence in the oriC region drastically changed the growth characteristics of the mutant strain. In comparison to the wild type, S. ghanaensis $\mathrm{O} 1$ grew in a very dispersed way, forming no mycelial clamps over the entire fermentation time course. Moreover, the mutant accumulated biomass much faster than the parental strain, indicating the deregulated chromosome replication and therefore increased cell division rate. As was previously described in S. coelicolor, with the time of growth in mycelial compartments AdpA reaches its highest levels [62], which leads to the inhibition of chromosome replication. Most likely, over-replication in S. ghanaensis O1 interferes with the processes involved in aggregation of hyphae, avoiding the formation of dense mycelial particles common for the wild-type strain. For example, in S. lividans there are several key factors participating in complex mechanisms of pellet formation. S. lividans mutants deficient in mat genes, which encode putative polysaccharide synthases involved in hyphae aggregation, form very small and open mycelia [12]. It is worth noting that in many streptomycetes overexpression of the cell-division activator protein SsgA had a major effect on mycelial morphology in submerged cultures, leading to the fragmented growth of mycelia [5]. Interestingly, in S. lividans and S. coelicolor the cellulose synthase-like protein CslA is responsible for an extracellular polysaccharide that determines the pellet morphology, with a dispersed morphology of $c s l A$ null mutants [63]. At the moment, we cannot fully explain the detailed mechanisms leading to the dispersed growth of S. ghanaensis $\mathrm{O}$. Whatever the real mechanism is, it is useful practically because an improved dispersed growth of strains is one of the key requirements for industrial utilization. Curiously, the very recent data provided by Płachetka et al. [64] have shown that the AdpA ortholog in Streptomyces venezuelae does not interact with its oriC region. Likely, this is one of the main factors explaining the dispersed growth common for $S$. venezuelae. Bioinformatical analysis of many streptomycetes genomes identified the presence of AdpAbs in oriC regions [29], suggesting that such mechanisms are omnipresent across Streptomyces spp. This fact points to the versatile genetic engineering strategy for improving the growth particularities of streptomycetes, producers of commercially important NPs.

Common for NP biosynthetic pathways, there are few final compounds accumulated during the fermentation course [65-67]. This strongly influences the industrial utilization of the producing microorganism, since it requires the expensive and complex rounds of purification to separate the desired molecule. Analogously, a complex of Mm produced by $S$. ghanaensis comprises a number of compounds with a slightly modified structure [15]. The three most abundant metabolites were $\mathrm{MmA}, \mathrm{NoB}$ and $\mathrm{MmG}$, which were almost equally accumulated and comprised the major fraction of Mm produced by the wild type under the tested conditions. Tremendous structural heterogeneity of many $\mathrm{Mm}$ is determined by the activity of amidotransferase MoeH5. Due to the broad substrate specificity, MoeH5 can introduce various modification to the "core" molecule NoA [38]. In this work, we employed a PCR mutagenesis-based strategy to eliminate moeH5 from the chromosome of producing strain. The used gene knockout system allows constructing marker- and "scar"-less deletions without introducing extra foreign DNA. In contrast to the well-known and widely used marker removal systems that utilize site-specific recombinases (e.g., Cre, Dre, Flp) $[68,69]$, leaving a short oligonucleotide region called "scar" that may limit further experiments [70], it permits creation of engineered strains with a virtually unlimited number of modifications. That is especially useful for the large genome optimization projects involving multiple genetic manipulations. The resulting double knockout mutant S. ghanaensis $\mathrm{O} 1 \Delta \mathrm{H} 5$ accumulated the growth benefits of the parental S. ghanaensis $\mathrm{O} 1$ strain and produced a significantly narrowed spectrum of $\mathrm{Mm}$ accumulating almost exclusively NoA. The strain may be used as a background for the chemoenzymatic synthesis of Mm analogues with altered biological activities. 
Biosynthesis of secondary metabolites in streptomycetes undergoes a fine-tune regulation at multiple levels. Usually, natural producers accumulate a relatively low amount of desired compound and antibiotic titer improvement is the main requirement for the industry. S. ghanaensis synthesizes Mm in milligram quantities, which has forced numerous investigations aimed to improving production levels. Because of the absence of cluster-situated regulators associated with moe genes, improvement of Mm biosynthesis is challenging. Some global regulators were shown to be involved in governing of $\mathrm{Mm}$ production in streptomycetes. In this study, we deleted the regulatory gene $w b l A_{g h}$ from the chromosome of $S$. ghanaensis $\mathrm{O} 1 \Delta \mathrm{H} 5$ using the aforementioned marker- and "scar"-less technique. The wblA orthologs are conserved across the Streptomyces genus and many studies, including that for Mm synthesis, reported them as negative regulators of antibiotic production [31-33]. Deletion of $w b l A_{g h}$ strongly increased NoA accumulation by the resulting triple mutant strain $S$. ghanaensis $\mathrm{O} 1 \Delta \mathrm{H} 5 \Delta \mathrm{wblA}$, while completely blocking the morphogenesis at the aerial mycelium level.

Successful genome engineering relies on an efficient and relatively easy way of DNA transfer into streptomycetes. Therefore, we evaluated the influence of applied genetic manipulations on the efficacy of DNA transfer in intergeneric conjugation between E. coli and S. ghanaensis. Interestingly, we observed a profound impact of substitution of $\mathrm{AdpA}_{\mathrm{gh}} \mathrm{bs}$ in the oriC region on the conjugal efficiency. In comparison to the wild-type strain, both pSET152 and pKC1139 were transferred with 2.5-3-fold higher frequency using S. ghanaensis $\mathrm{O} 1$ as a recipient. Likely, the way that the mutant grows is the most plausible explanation of the increased conjugal ability. In contrast to the parental strain, which forms dense and large mycelial particles that would limit the physical contacts with donor cells, S. ghanaensis $\mathrm{O} 1$ produces almost no mycelial pellets, establishing an efficient and close contact between interacting cells. As anticipated, deletion of amidotransferase moeH5 did not influence the morphological progression and resulted in no changes in the exconjugants occurrence compared to $S$. ghanaensis O1. Lastly, the frequency of conjugation was greatly reduced when $S$. ghanaensis $\mathrm{O} 1 \Delta \mathrm{H} 5 \Delta$ wblA was used as a recipient strain. This perfectly correlates with the inability of the $w b l A_{g h}$-defficient mutant to produce spores. Even though we used an equal amount of recipient cells ( $10^{7} \mathrm{cfu}$ ), the exconjugants occurrence was decreased more than 6-fold when compared to S. ghanaensis $\mathrm{O} 1 \Delta \mathrm{H} 5$. In many tested cases, the conjugal efficiency was shown to be much higher when a spore suspension rather than mycelium was used $[39,71,72]$. Therefore, despite the increased NoA production in $S$. ghanaensis $\mathrm{O} 1 \Delta \mathrm{H} 5 \Delta \mathrm{wblA}$, its further utilization might be limited in experiments demanding a high efficiency of conjugation.

\section{Conclusions}

In this work, we employed genome engineering approaches to construct $S$. ghanaensis strains with improved growth and antibiotic production characteristics. First, we in vivo substituted $\mathrm{AdpA}_{\mathrm{gh}}$ bs in the oriC region in the $S$. ghanaensis chromosome. Strikingly, in contrast to the wild type, the mutant $S$. ghanaensis $\mathrm{O} 1$ strain grew in a dispersed way, forming no mycelial pellets and displaying an accelerated growth rate. Moreover, the maximum Mm biosynthesis was observed $24 \mathrm{~h}$ in advance in the mutant compared to the parental strain. Next, a marker- and "scar"-less elimination of the amidotransferase gene moeH5 greatly reduced the spectrum of Mm produced by $S$. ghanaensis $\mathrm{O} 1 \Delta \mathrm{H} 5$, leading to the accumulation of almost exclusively NoA. Additionally, knockout of the negative regulator of antibiotic production $w b l A_{g h}$ strongly improved the NoA biosynthetic titers but resulted in a strain deficient in sporulation. Finally, we compared the efficiency of DNA transfer using intergeneric conjugation with E. coli. We observed the strong beneficial effect of the $A d p A_{\text {gh }}$ bs substitution on the frequency of exconjugants occurrence, whereas deletion of $w b l A_{g h}$ drastically reduced the conjugal efficacy. Overall, we constructed a triple mutant carrying no extra foreign DNA, whose type and accelerated growth, narrowed spectrum and increased level of antibiotic synthesis are clearly supreme over the original 
strain. The technology described in this paper can be useful background information for further projects focused on production titers optimization in other strains.

Supplementary Materials: The following supporting information can be downloaded at: https: / /www.mdpi.com/article/10.3390/microorganisms10010030/s1, Figure S1: Morphology of the S. ghanaensis strains grown in TSB for $24 \mathrm{~h}$. Table S1: Strains and plasmids used in this work. Table S2: Primers used in this work.

Author Contributions: Project design and conceptualization, R.M.; methodology, R.M. and O.T.; experimental procedures, R.M. and O.T.; investigation, R.M. and O.T.; resources, A.B.; writing—original draft preparation, R.M.; writing-review and editing, R.M., O.T. and A.B.; funding acquisition, A.B. All authors have read and agreed to the published version of the manuscript.

Funding: This research was funded by the Deutsche Forschungsgemeinschaft (DFG, German Research Foundation)—235777276/GRK1976 (awarded to A.B.).

Institutional Review Board Statement: Not applicable.

Informed Consent Statement: Not applicable.

Data Availability Statement: The data presented in this study are available in this article and Supplementary Materials.

Acknowledgments: We are grateful to Judy Wong for proofreading the manuscript and to Ralf Thomann for technical assistance in SEM.

Conflicts of Interest: The authors declare no conflict of interest.

\section{References}

1. Barka, E.A.; Vatsa, P.; Sanchez, L.; Gaveau-Vaillant, N.; Jacquard, C.; Meier-Kolthoff, J.P.; Klenk, H.-P.; Clément, C.; Ouhdouch, Y.; van Wezel, G.P. Taxonomy, Physiology, and Natural Products of Actinobacteria. Microbiol. Mol. Biol. Rev. 2016, 80, 1-43. [CrossRef]

2. Vrancken, K.; Anné, J. Secretory production of recombinant proteins by Streptomyces. Future Microbiol. 2009, 4, 181-188. [CrossRef] [PubMed]

3. Claessen, D.; Rozen, D.E.; Kuipers, O.P.; Søgaard-Andersen, L.; van Wezel, G.P. Bacterial solutions to multicellularity: A tale of biofilms, filaments and fruiting bodies. Nat. Rev. Microbiol. 2014, 12, 115-124. [CrossRef]

4. Flärdh, K.; Buttner, M.J. Streptomyces morphogenetics: Dissecting differentiation in a filamentous bacterium. Nat. Rev. Microbiol. 2009, 7, 36-49. [CrossRef]

5. Van Wezel, G.P.; Krabben, P.; Traag, B.A.; Keijser, B.J.F.; Kerste, R.; Vijgenboom, E.; Heijnen, J.J.; Kraal, B. Unlocking Streptomyces spp. for use as sustainable industrial production platforms by morphological engineering. Appl. Environ. Microbiol. 2006, 72, 5283-5288. [CrossRef]

6. Gomes, J.; Menawat, A.S. Fed-batch bioproduction of spectinomycin. Adv. Biochem. Eng. Biotechnol. 1998, 59, 1-46. [CrossRef]

7. Nielsen, J. Modelling the morphology of filamentous microorganisms. Trends Biotechnol. 1996, 14, 438-443. [CrossRef]

8. Van Dissel, D.; Claessen, D.; van Wezel, G.P. Morphogenesis of Streptomyces in submerged cultures. Adv. Appl. Microbiol. 2014, 89, 1-45. [CrossRef] [PubMed]

9. Celler, K.; Picioreanu, C.; van Loosdrecht, M.C.M.; van Wezel, G.P. Structured morphological modeling as a framework for rational strain design of Streptomyces species. Antonie Van Leeuwenhoek 2012, 102, 409-423. [CrossRef] [PubMed]

10. Chaplin, A.K.; Petrus, M.L.C.; Mangiameli, G.; Hough, M.A.; Svistunenko, D.A.; Nicholls, P.; Claessen, D.; Vijgenboom, E.; Worrall, J.A.R. GlxA is a new structural member of the radical copper oxidase family and is required for glycan deposition at hyphal tips and morphogenesis of Streptomyces lividans. Biochem. J. 2015, 469, 433-444. [CrossRef]

11. Petrus, M.L.C.; Vijgenboom, E.; Chaplin, A.K.; Worrall, J.A.R.; van Wezel, G.P.; Claessen, D. The DyP-type peroxidase DtpA is a Tat-substrate required for GlxA maturation and morphogenesis in Streptomyces. Open Biol. 2016, 6, 150149. [CrossRef]

12. Van Dissel, D.; Claessen, D.; Roth, M.; van Wezel, G.P. A novel locus for mycelial aggregation forms a gateway to improved Streptomyces cell factories. Microb. Cell Fact. 2015, 14, 44. [CrossRef] [PubMed]

13. Zacchetti, B.; Smits, P.; Claessen, D. Dynamics of Pellet Fragmentation and Aggregation in Liquid-Grown Cultures of Streptomyces lividans. Front. Microbiol. 2018, 9, 943. [CrossRef] [PubMed]

14. Ostash, B.; Saghatelian, A.; Walker, S. A streamlined metabolic pathway for the biosynthesis of moenomycin A. Chem. Biol. 2007, 14, 257-267. [CrossRef] [PubMed]

15. Ostash, B.; Walker, S. Moenomycin family antibiotics: Chemical synthesis, biosynthesis, and biological activity. Nat. Prod. Rep. 2010, 27, 1594-1617. [CrossRef] [PubMed] 
16. Lopatniuk, M.; Ostash, B.; Luzhetskyy, A.; Walker, S.; Fedorenko, V. Generation and study of the strains of streptomycetesHeterologous hosts for production of moenomycin. Russ. J. Genet. 2014, 50, 360-365. [CrossRef] [PubMed]

17. Makitrynskyy, R.; Rebets, Y.; Ostash, B.; Zaburannyi, N.; Rabyk, M.; Walker, S.; Fedorenko, V. Genetic factors that influence moenomycin production in streptomycetes. J. Ind. Microbiol. Biotechnol. 2010, 37, 559-566. [CrossRef]

18. Rabyk, M.; Ostash, B.; Rebets, Y.; Walker, S.; Fedorenko, V. Streptomyces ghanaensis pleiotropic regulatory gene wblA(gh) influences morphogenesis and moenomycin production. Biotechnol. Lett. 2011, 33, 2481-2486. [CrossRef]

19. Makitrynskyy, R.; Ostash, B.; Tsypik, O.; Rebets, Y.; Doud, E.; Meredith, T.; Luzhetskyy, A.; Bechthold, A.; Walker, S.; Fedorenko, V. Pleiotropic regulatory genes $b l d A, a d p A$ and $a b s B$ are implicated in production of phosphoglycolipid antibiotic moenomycin. Open Biol. 2013, 3, 130121. [CrossRef]

20. Mutenko, H.; Makitrinskyy, R.; Tsypik, O.; Walker, S.; Ostash, B.; Fedorenko, V. Genes for biosynthesis of butenolide-like signalling molecules in Streptomyces ghanaensis, their role in moenomycin production. Russ. J. Genet. 2014, 50, 563-568. [CrossRef]

21. Kuzhyk, Y.; Mutenko, H.; Fedorenko, V.; Ostash, B. Analysis of Streptomyces ghanaensis ATCC14672 gene SSFG_07725 for putative $\gamma$-butyrolactone synthase. Folia Microbiol. 2018, 63, 701-706. [CrossRef] [PubMed]

22. Sehin, Y.; Koshla, O.; Dacyuk, Y.; Zhao, R.; Ross, R.; Myronovskyi, M.; Limbach, P.A.; Luzhetskyy, A.; Walker, S.; Fedorenko, V.; et al. Gene ssfg_01967 (miaB) for tRNA modification influences morphogenesis and moenomycin biosynthesis in Streptomyces ghanaensis ATCC14672. Microbiology 2019, 165, 233-245. [CrossRef] [PubMed]

23. Kuzhyk, Y.; Lopatniuk, M.; Luzhetskyy, A.; Fedorenko, V.; Ostash, B. Genome Engineering Approaches to Improve Nosokomycin A Production by Streptomyces ghanaensis B38.3. Indian J. Microbiol. 2019, 59, 109-111. [CrossRef]

24. Makitrynskyy, R.; Tsypik, O.; Nuzzo, D.; Paululat, T.; Zechel, D.L.; Bechthold, A. Secondary nucleotide messenger c-di-GMP exerts a global control on natural product biosynthesis in streptomycetes. Nucleic Acids Res. 2020, 48, 1583-1598. [CrossRef]

25. Nuzzo, D.; Makitrynskyy, R.; Tsypik, O.; Bechthold, A. Cyclic di-GMP cyclase SSFG_02181 from Streptomyces ghanaensis ATCC14672 regulates antibiotic biosynthesis and morphological differentiation in streptomycetes. Sci. Rep. 2020, 10, 12021. [CrossRef]

26. Nuzzo, D.; Makitrynskyy, R.; Tsypik, O.; Bechthold, A. Identification and Characterization of Four c-di-GMP-Metabolizing Enzymes from Streptomyces ghanaensis ATCC14672 Involved in the Regulation of Morphogenesis and Moenomycin A Biosynthesis. Microorganisms 2021, 9, 284. [CrossRef] [PubMed]

27. Higo, A.; Hara, H.; Horinouchi, S.; Ohnishi, Y. Genome-wide distribution of AdpA, a global regulator for secondary metabolism and morphological differentiation in Streptomyces, revealed the extent and complexity of the AdpA regulatory network. DNA Res. 2012, 19, 259-273. [CrossRef]

28. Zhang, S.; Klementz, D.; Zhu, J.; Makitrynskyy, R.; Ola Pasternak, A.R.; Günther, S.; Zechel, D.L.; Bechthold, A. Genome mining reveals the origin of a bald phenotype and a cryptic nucleocidin gene cluster in Streptomyces asterosporus DSM 41452 . J. Biotechnol. 2019, 292, 23-31. [CrossRef]

29. Wolański, M.; Jakimowicz, D.; Zakrzewska-Czerwińska, J. AdpA, key regulator for morphological differentiation regulates bacterial chromosome replication. Open Biol. 2012, 2, 120097. [CrossRef]

30. Yu, P.; Liu, S.-P.; Bu, Q.-T.; Zhou, Z.-X.; Zhu, Z.-H.; Huang, F.-L.; Li, Y.-Q. WblAch, a pivotal activator of natamycin biosynthesis and morphological differentiation in Streptomyces chattanoogensis L10, is positively regulated by AdpAch. Appl. Environ. Microbiol. 2014, 80, 6879-6887. [CrossRef]

31. Lu, C.; Liao, G.; Zhang, J.; Tan, H. Identification of novel tylosin analogues generated by a wblA disruption mutant of Streptomyces ansochromogenes. Microb. Cell Fact. 2015, 14, 173. [CrossRef] [PubMed]

32. Zhang, F.; Gao, D.; Lin, J.; Zhu, M.; Zhuang, Z.; Duan, Y.; Zhu, X. Construction of Inducible Genetic Switch for the Global Regulator WblA to Sustain Both Overproduction of Tiancimycins and On-Demand Sporulation in Streptomyces sp. CB03234. ACS Synth. Biol. 2020, 9, 1460-1467. [CrossRef]

33. Huang, H.; Hou, L.; Li, H.; Qiu, Y.; Ju, J.; Li, W. Activation of a plasmid-situated type III PKS gene cluster by deletion of a wbl gene in deepsea-derived Streptomyces somaliensis SCSIO ZH66. Microb. Cell Fact. 2016, 15, 116. [CrossRef]

34. Nah, H.-J.; Park, J.; Choi, S.; Kim, E.-S. WblA, a global regulator of antibiotic biosynthesis in Streptomyces. J. Ind. Microbiol. Biotechnol. 2021, 48. [CrossRef]

35. Green, M.R.; Sambrook, J. Molecular Cloning: A Laboratory Manual, 4th ed.; Green, M.R., Sambrook, J., Eds.; Cold Spring Harbor Laboratory Press: New York, NY, USA, 2012; ISBN 9781936113422.

36. Myronovskyi, M.; Welle, E.; Fedorenko, V.; Luzhetskyy, A. Beta-glucuronidase as a sensitive and versatile reporter in actinomycetes. Appl. Environ. Microbiol. 2011, 77, 5370-5383. [CrossRef]

37. Zakrzewska-Czerwińska, J.; Majka, J.; Schrempf, H. Minimal requirements of the Streptomyces lividans 66 oriC region and its transcriptional and translational activities. J. Bacteriol. 1995, 177, 4765-4771. [CrossRef]

38. Ostash, B.; Campbell, J.; Luzhetskyy, A.; Walker, S. MoeH5: A natural glycorandomizer from the moenomycin biosynthetic pathway. Mol. Microbiol. 2013, 90, 1324-1338. [CrossRef]

39. Kieser, T. Practical Streptomyces Genetics; John Innes Foundation: Norwich, UK, 2000; ISBN 0708406238.

40. Ostash, B.; Makitrinskyy, R.; Walker, S.; Fedorenko, V. Identification and characterization of Streptomyces ghanaensis ATCC14672 integration sites for three actinophage-based plasmids. Plasmid 2009, 61, 171-175. [CrossRef] 
41. Muth, G. The pSG5-based thermosensitive vector family for genome editing and gene expression in actinomycetes. Appl. Microbiol. Biotechnol. 2018, 102, 9067-9080. [CrossRef] [PubMed]

42. Murray, B.E. Vancomycin-resistant enterococcal infections. N. Engl. J. Med. 2000, 342, 710-721. [CrossRef] [PubMed]

43. Silver, L.L. Challenges of antibacterial discovery. Clin. Microbiol. Rev. 2011, 24, 71-109. [CrossRef]

44. Baltz, R.H. Natural product drug discovery in the genomic era: Realities, conjectures, misconceptions, and opportunities. J. Ind. Microbiol. Biotechnol. 2019, 46, 281-299. [CrossRef]

45. Baltz, R.H. Gifted microbes for genome mining and natural product discovery. J. Ind. Microbiol. Biotechnol. 2017, 44, 573-588. [CrossRef]

46. Ochi, K.; Hosaka, T. New strategies for drug discovery: Activation of silent or weakly expressed microbial gene clusters. Appl. Microbiol. Biotechnol. 2013, 97, 87-98. [CrossRef] [PubMed]

47. Rutledge, P.J.; Challis, G.L. Discovery of microbial natural products by activation of silent biosynthetic gene clusters. Nat. Rev. Microbiol. 2015, 13, 509-523. [CrossRef] [PubMed]

48. Zhu, H.; Sandiford, S.K.; van Wezel, G.P. Triggers and cues that activate antibiotic production by actinomycetes. J. Ind. Microbiol. Biotechnol. 2014, 41, 371-386. [CrossRef]

49. Yoon, V.; Nodwell, J.R. Activating secondary metabolism with stress and chemicals. J. Ind. Microbiol. Biotechnol. 2014, 41, 415-424. [CrossRef]

50. Huber, G.; Schacht, U.; Weidenmüller, H.L.; Schmidt-Thomé, J.; Duphorn, J.; Tschesche, R. Meonomycin, a new antibiotic. II. Characterization and chemistry. Antimicrob. Agents Chemother. 1965, 5, 737-742. [PubMed]

51. Wallhausser, K.H.; Nesemann, G.; Prave, P.; Steigler, A. Moenomycin, a new antibiotic. I. Fermentation and isolation. Antimicrob. Agents Chemother. 1965, 5, 734-736.

52. Ostash, B.; Walker, S. Bacterial transglycosylase inhibitors. Curr. Opin. Chem. Biol. 2005, 9, 459-466. [CrossRef]

53. Goldman, R.C.; Gange, D. Inhibition of transglycosylation involved in bacterial peptidoglycan synthesis. Curr. Med. Chem. 2000, 7, 801-820. [CrossRef]

54. Halliday, J.; McKeveney, D.; Muldoon, C.; Rajaratnam, P.; Meutermans, W. Targeting the forgotten transglycosylases. Biochem. Pharmacol. 2006, 71, 957-967. [CrossRef]

55. Kempin, U.; Hennig, L.; Müller, D.; Markus, A.; Welzel, P. A selective reaction that can be used to attach moenomycin to solid supports and proteins. Tetrahedron Lett. 1996, 37, 5087-5090. [CrossRef]

56. Rühl, T.; Daghish, M.; Buchynskyy, A.; Barche, K.; Volke, D.; Stembera, K.; Kempin, U.; Knoll, D.; Hennig, L.; Findeisen, M.; et al. Studies on the interaction of the antibiotic moenomycin A with the enzyme penicillin-binding protein 1b. Bioorg. Med. Chem. 2003, 11, 2965-2981. [CrossRef]

57. Yu, J.-Y.; Cheng, H.-J.; Wu, H.-R.; Wu, W.-S.; Lu, J.-W.; Cheng, T.-J.; Wu, Y.-T.; Fang, J.-M. Structure-based design of bacterial transglycosylase inhibitors incorporating biphenyl, amine linker and 2-alkoxy-3-phosphorylpropanoate moieties. Eur. J. Med. Chem. 2018, 150, 729-741. [CrossRef]

58. Zuegg, J.; Muldoon, C.; Adamson, G.; McKeveney, D.; Le Thanh, G.; Premraj, R.; Becker, B.; Cheng, M.; Elliott, A.G.; Huang, J.X.; et al. Carbohydrate scaffolds as glycosyltransferase inhibitors with in vivo antibacterial activity. Nat. Commun. 2015, 6, 7719. [CrossRef] [PubMed]

59. Taylor, J.G.; Li, X.; Oberthür, M.; Zhu, W.; Kahne, D.E. The total synthesis of moenomycin A. J. Am. Chem. Soc. 2006, 128, 15084-15085. [CrossRef]

60. Pfaller, M.A. Flavophospholipol use in animals: Positive implications for antimicrobial resistance based on its microbiologic properties. Diagn. Microbiol. Infect. Dis. 2006, 56, 115-121. [CrossRef] [PubMed]

61. Butaye, P.; Devriese, L.A.; Haesebrouck, F. Differences in antibiotic resistance patterns of Enterococcus faecalis and Enterococcus faecium strains isolated from farm and pet animals. Antimicrob. Agents Chemother. 2001, 45, 1374-1378. [CrossRef]

62. Wolanski, M.; Donczew, R.; Kois-Ostrowska, A.; Masiewicz, P.; Jakimowicz, D.; Zakrzewska-Czerwinska, J. The level of AdpA directly affects expression of developmental genes in Streptomyces coelicolor. J. Bacteriol. 2011, 193, 6358-6365. [CrossRef]

63. Xu, H.; Chater, K.F.; Deng, Z.; Tao, M. A cellulose synthase-like protein involved in hyphal tip growth and morphological differentiation in streptomyces. J. Bacteriol. 2008, 190, 4971-4978. [CrossRef] [PubMed]

64. Płachetka, M.; Krawiec, M.; Zakrzewska-Czerwińska, J.; Wolański, M. AdpA Positively Regulates Morphological Differentiation and Chloramphenicol Biosynthesis in Streptomyces venezuelae. Microbiol. Spectr. 2021, 9, e0198121. [CrossRef]

65. Tsypik, O.; Makitrynskyy, R.; Frensch, B.; Zechel, D.L.; Paululat, T.; Teufel, R.; Bechthold, A. Oxidative Carbon Backbone Rearrangement in Rishirilide Biosynthesis. J. Am. Chem. Soc. 2020, 142, 5913-5917. [CrossRef]

66. Tsypik, O.; Makitrynskyy, R.; Yan, X.; Koch, H.-G.; Paululat, T.; Bechthold, A. Regulatory Control of Rishirilide(s) Biosynthesis in Streptomyces bottropensis. Microorganisms 2021, 9, 374. [CrossRef] [PubMed]

67. Ding, N.; Jiang, Y.; Han, L.; Chen, X.; Ma, J.; Qu, X.; Mu, Y.; Liu, J.; Li, L.; Jiang, C.; et al. Bafilomycins and Odoriferous Sesquiterpenoids from Streptomyces albolongus Isolated from Elephas maximus Feces. J. Nat. Prod. 2016, 79, 799-805. [CrossRef]

68. Herrmann, S.; Siegl, T.; Luzhetska, M.; Petzke, L.; Jilg, C.; Welle, E.; Erb, A.; Leadlay, P.F.; Bechthold, A.; Luzhetskyy, A. Site-specific recombination strategies for engineering actinomycete genomes. Appl. Environ. Microbiol. 2012, 78, 1804-1812. [CrossRef]

69. Fedoryshyn, M.; Petzke, L.; Welle, E.; Bechthold, A.; Luzhetskyy, A. Marker removal from actinomycetes genome using Flp recombinase. Gene 2008, 419, 43-47. [CrossRef] [PubMed] 
70. Lopatniuk, M.; Ostash, B.; Makitrynskyy, R.; Walker, S.; Luzhetskyy, A.; Fedorenko, V. Testing the utility of site-specific recombinases for manipulations of genome of moenomycin producer Streptomyces ghanaensis ATCC14672. J. Appl. Genet. 2015, 56, 547-550. [CrossRef] [PubMed]

71. Bierman, M.; Logan, R.; O’Brien, K.; Seno, E.T.; Nagaraja Rao, R.; Schoner, B.E. Plasmid cloning vectors for the conjugal transfer of DNA from Escherichia coli to Streptomyces spp. Gene 1992, 116, 43-49. [CrossRef]

72. Mazodier, P.; Petter, R.; Thompson, C. Intergeneric conjugation between Escherichia coli and Streptomyces species. J. Bacteriol. 1989, 171, 3583-3585. [CrossRef] 